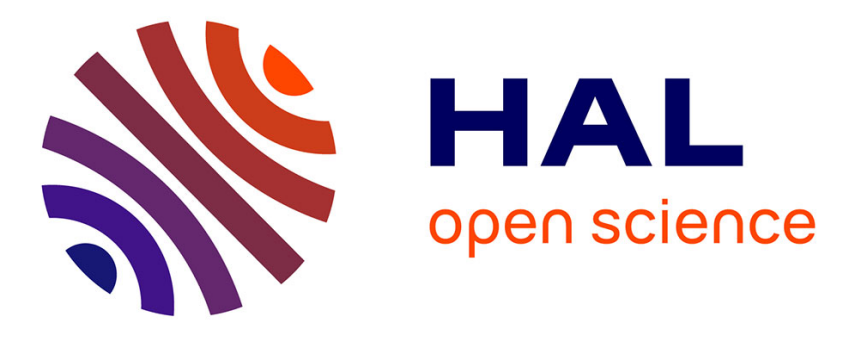

\title{
Spreading of transverse compressive stresses in glued laminated timber
}

\author{
Damien Lathuilliere, Octavian Pop, Laurent Bléron, Frédéric Dubois, Fazia \\ Fouchal, Jean-François Bocquet
}

\section{To cite this version:}

Damien Lathuilliere, Octavian Pop, Laurent Bléron, Frédéric Dubois, Fazia Fouchal, et al.. Spreading of transverse compressive stresses in glued laminated timber. European Journal of Wood and Wood Products, 2015, 73 (4), pp.475-484. 10.1007/s00107-015-0922-0 . hal-01599802

\section{HAL Id: hal-01599802 \\ https://hal.univ-lorraine.fr/hal-01599802}

Submitted on 11 Oct 2017

HAL is a multi-disciplinary open access archive for the deposit and dissemination of scientific research documents, whether they are published or not. The documents may come from teaching and research institutions in France or abroad, or from public or private research centers.
L'archive ouverte pluridisciplinaire HAL, est destinée au dépôt et à la diffusion de documents scientifiques de niveau recherche, publiés ou non, émanant des établissements d'enseignement et de recherche français ou étrangers, des laboratoires publics ou privés. 


\title{
Spreading of transverse compressive stresses in glued laminated timber
}

\author{
Damien Lathuilliere ${ }^{1,3} \cdot$ Octavian Pop $^{2} \cdot$ Laurent Bléron $^{1} \cdot$ Frédéric Dubois $^{2} \cdot$ Fazia Fouchal $^{2} \cdot$ \\ Jean-François Bocquet ${ }^{1}$
}

\begin{abstract}
This paper presents a new approach for understanding localized compressive behavior perpendicular to the grain based on beams subjected to three-point bending. It was intended to take into account the coupling between compressive stresses perpendicular to the grain due to support reactions and shear stresses. To validate this, model, results of compression tests have been examined. The digital image correlation (DIC) method has been applied in order to analyze the deformation fields in support areas. The tests allow confirming the presence of spreading effect in the vicinity of support areas according to the DIC method. An analytical formulation has therefore been proposed to quantify distribution versus increasing compressive strength perpendicular to the grain, including shear effects. A scale effect and support conditions have also been highlighted using three different geometries and two types of tests.
\end{abstract}

\section{Introduction}

\subsection{Compression and bending tests}

The use of glued laminated timber beams enables designing large-spanned structures and contributes to developing

Damien Lathuilliere

damien.lathuilliere@univ-lorraine.fr

1 Laboratoire d'Etude et de recherche sur le matériau bois, LERMAB, ENSTIB, Université de Lorraine, 27 rue du Merle Blanc, BP 1041, 88051 Epinal Cedex 9, France

2 Groupe d'étude des matériaux hétérogènes, GEMH, Centre Universitaire de Génie Civil, Université de Limoges, Boulevard Jacques Derche, 19300 Egletons, France

3 SFS Intec SAS, 39, rue Georges Méliès, BP 55, 26902 Valence Cedex 9, France timber structures in the field of civil engineering. However, the glued laminated timber is characterized by small support length compared to span of industrial building. These supports concentrate the compressive stress perpendicular to the grain combined with a shear state. Given this state, two approaches can be studied. The first pertains to support reinforcement techniques (Blass and Bejtka 2004). The second, which is the focus of this paper, seeks to understand the stress distribution in the vicinity of support areas in coupling a compressive gradient perpendicular to the grain between the base and top fibers with the shear stress state induced by the bending configuration (see Fig. 1).

In the same context, both Blass and Görlacher (2004) and Ed and Hasselqvist (2011) conducted studies with respect to compressive stresses perpendicular to the grain on bending beams. The vertical displacement is recorded using an LVDT transducer without observing the distribution area or the loaded volume in the vicinity of support areas. In reality, for a bending test, the compressive stress perpendicular to the grain presents a non-uniform gradient along its height, as given by Leijten et al. (2012). As a result of these considerations, the current study must integrate the bending state.

However, the compressive behavior perpendicular to the grain has to be known without the distribution effect. In this context, two specific approaches can be identified, yet both rely on a direct compression test perpendicular to the grain. The first approach, proposed by the European Community, is based on actual mechanical behavior whereby compression direction perpendicular to the grain is tested according to EN 408 standard. This test consists of applying a uniform load onto the $45 \times 70-\mathrm{mm}^{2}$ top surface of a cubic test piece of $90 \mathrm{~mm}$ high, as shown in Fig. 2, case A. The North American practice proposes an alternative approach, based on a technological approach 
Fig. 1 Stress distribution around the contact surface

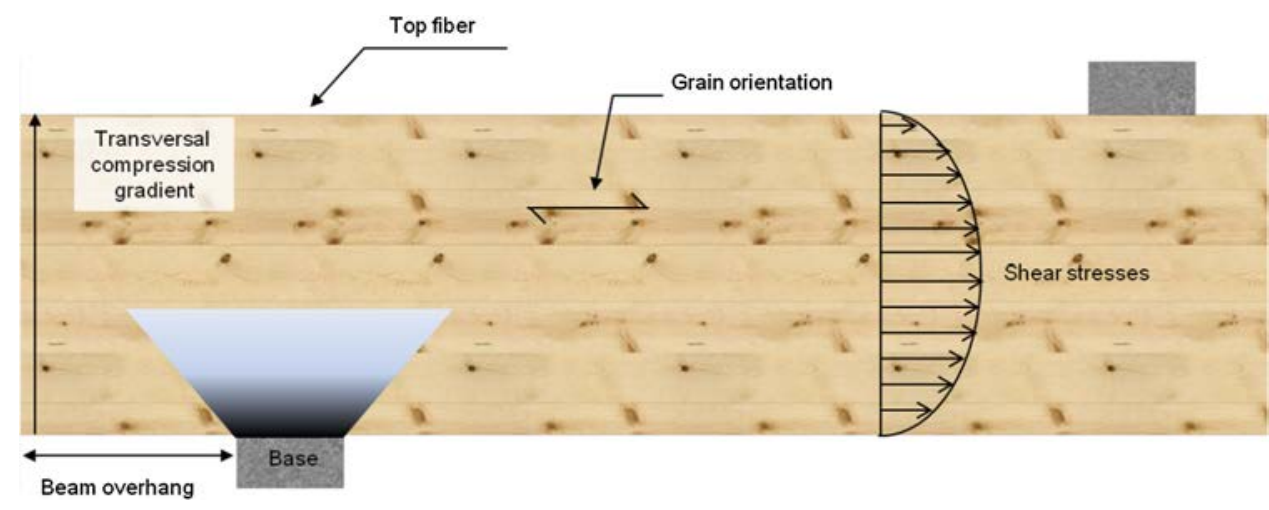

Fig. 2 Test configurations

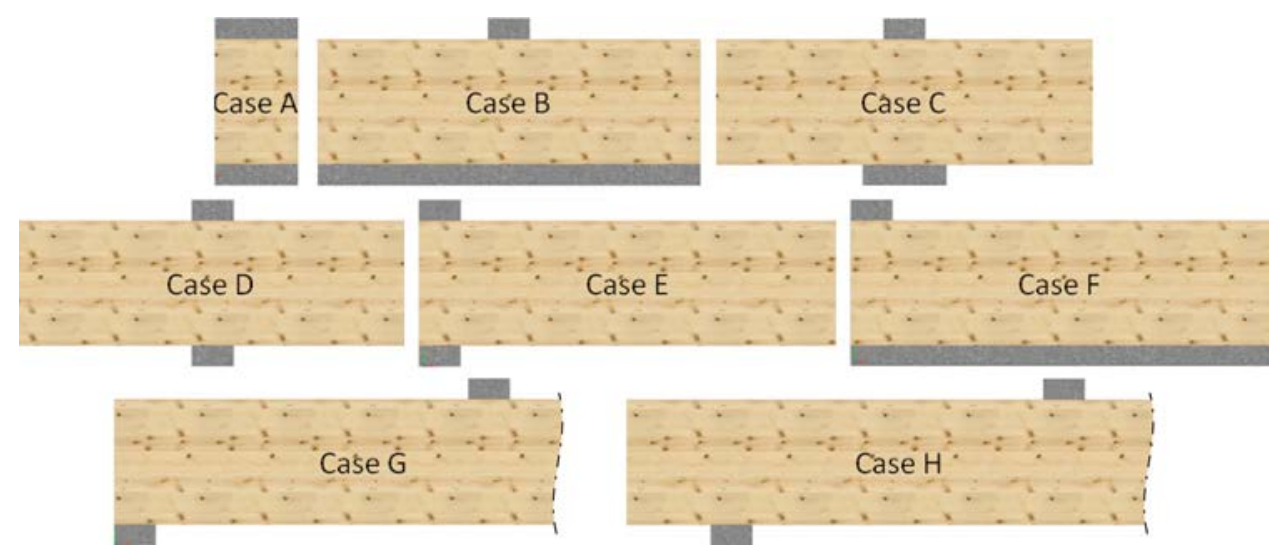

according to ASTM D143 standard. According to this second case, the $50 \times 50 \times 150-\mathrm{mm}^{3}$ piece is loaded in the middle section across a steel plate with a $50 \times 50-\mathrm{mm}^{2}$ surface area distribution (Fig. 2, case B).

At present, several configurations tested are proposed in the literature (Fig. 2), as summarized in Table 1 for glued laminated timber. It exists of two configuration types. The first is the compression test with configurations of $\mathrm{A}-\mathrm{F}$, the second is the bending test with configurations $\mathrm{G}$ and $\mathrm{H}$. Kollmann (1955) showed several results from tests A and C. The type $\mathrm{C}$ test includes a variation in the support length. For an equivalent vertical displacement value, test results indicate an increase in stress as the support length decreases. Indeed, the stress is proportional to the support surface and indirectly to the support length that is why these tests demonstrate the presence of a spreading effect on the loaded volume.

\subsection{Spreading factor}

In order to highlight the spreading effect, Riberholt (2000) proposed to introduce the spreading factor $\left(k_{d i f}\right)$, as the ratio between the compressive stress perpendicular to the grain $\left(\sigma_{c, 90}\right)$ and the compressive strength perpendicular to the grain $\left(f_{c, 90}\right)$, deducted from the European standard EN 408. $k_{d i f}=\frac{\sigma_{c, 90}}{f_{c, 90}}$

Several researchers (Madsen 1992; Blass and Görlacher 2004; Van der Put 2008; Bléron et al. 2009) have previously proposed various models predicting the compressive behavior perpendicular to the grain taking into account the spreading effect. The model evolution shows the integration of the geometry data of the sample over time. Today, the current model of European timber design code, EN 1995-1-1 A1 is the second model. It is written in such a way that the resistance part has to be lower than the active part:

$f_{c, 90, d} \cdot k_{c, 90} \geq \frac{F_{c, 90, d}}{b \cdot l_{e f}}$

However, the standard allows an increase of the design compressive strength perpendicular to the grain $\left(f_{c, 90, k}\right)$ via the factor $\left(k_{c, 90}\right)$ taking into account the load configuration. For glued laminated timber on discrete support whose length is $<400 \mathrm{~mm}$, it is equal to 1.75 . In other cases, it is equal to 1 . Furthermore, it allows a reduction of the active stress by means of designing of an effective length $\left(l_{\mathrm{ef}}\right)$. The common case for the design of an effective length is the addition of $30 \mathrm{~mm}$ on either side of the support, if the sample is long enough. 
Table 1 Literature review on uniform compressive stress tests

\begin{tabular}{|c|c|c|c|c|c|c|}
\hline \multirow[t]{2}{*}{ References } & \multicolumn{3}{|c|}{ Sample size } & \multirow{2}{*}{$\begin{array}{l}\text { Test configuration } \\
\text { (Fig. 2) }\end{array}$} & \multirow{2}{*}{$\begin{array}{l}\text { Compressive strength } \\
\text { perpendicular to the } \\
\text { grain }\left(\mathrm{N} / \mathrm{mm}^{2}\right)\end{array}$} & \multirow[t]{2}{*}{ Strain $(\%)$} \\
\hline & $\begin{array}{l}\text { Height } \\
\text { (h) }(\mathrm{mm})\end{array}$ & $\begin{array}{l}\text { Width } \\
\text { (b) (mm) }\end{array}$ & $\begin{array}{l}\text { Support } \\
\text { length } l_{s}(\mathrm{~mm})\end{array}$ & & & \\
\hline \multirow[t]{3}{*}{ Blass and Görlacher (2004) } & 50 & 120 & 100 & $\mathrm{~A}, \mathrm{~B}, \mathrm{D}$ & 3.3 & 1 \\
\hline & 100 & & & & & \\
\hline & 200 & & & & & \\
\hline Mähr (2002) & 140 & 140 & 280 & $\mathrm{~A}, \mathrm{~B}$ & 2.9 & 1 \\
\hline \multirow[t]{2}{*}{ Augustin et al. (2006) } & 200 & 160 & 160 & $\mathrm{~A}, \mathrm{~B}, \mathrm{~F}$ & 2.87 & 1 \\
\hline & & & & & 3.31 & \\
\hline Nilsson (2002) & 315 & 90 & 150 & $\mathrm{~A}, \mathrm{~B}$ & 3 & 1 \\
\hline \multirow[t]{2}{*}{ Reichegger (2004) } & 400 & 120 & 200 & $\mathrm{~A}, \mathrm{~B}$ & 3.3 & 1 \\
\hline & 600 & & & & & \\
\hline \multirow[t]{2}{*}{ Ed and Hasselqvist (2011) } & 90 & 90 & 135 & $\mathrm{~A}, \mathrm{G}$ & 3.5 & 1 \\
\hline & 115 & 115 & & & & \\
\hline Bléron et al. (2009) & 300 & 78 & 100 & $\mathrm{~A}, \mathrm{~B}, \mathrm{D}, \mathrm{E}$ & 3.0 & 1 \\
\hline
\end{tabular}

The Eurocode 5 criterion can be modified in another equivalent form. The two factors $k_{c, 90}$ and $l_{e f}$ are expressed as a single factor, allowing the integration into the spreading factor normative $\left(k_{d i f, E C 5}\right)$ with Eq. (3).

In that case, the active stress is calculated by the ratio between the design compressive load perpendicular to the grain $\left(F_{c, 90, d}\right)$ and the product between the support length $\left(l_{s}\right)$ and the width $(b)$.

$f_{c, 90, d} \cdot k_{d i f, E C 5} \geq \frac{F_{c, 90, d}}{b \cdot l_{s}}=\sigma_{c, 90, d} \quad$ with

$k_{d i f, E C 5}=k_{c, 90} \cdot \frac{l_{e f}}{l_{s}}$

\subsection{Objectives}

This study features a complementary experimental approach that highlights the stress distribution in the vicinity of support areas. The spreading effect and compressive gradient perpendicular to the grain are studied in the vicinity of support areas for bending and direct compression configurations. This approach is based on a digital image correlation (DIC) technique that allows identifying the elastic and plastic areas, in order to incorporate a height effect.

The experimental protocol is presented in the next section; it is based on a three-point bending test conducted using a DIC device. The hydraulic machine generates an asymmetric loading that serves to amplify compression perpendicular to the grain in the vicinity of support areas.

The DIC method is further explained in Sect. 3. For one thing, this technique makes it possible to focus on the spreading of compressive strain perpendicular to the grain in the vicinity of support areas. Moreover, the full displacement field illustrates a non-gradient linearity that induces a height effect.

The final part of this paper analyzes the results obtained. The stress distribution is also evaluated in an effort to propose a corrective function for the ultimate compressive stress calculation. The necessity of introducing a scale effect is discussed in the conclusion.

\section{Materials and methods}

\subsection{Bending tests}

\subsubsection{Samples and their respective geometries}

The wood used is homogeneous glued laminated timber of GL24H class, composed of $45 \mathrm{~mm}$ thick spruce (Picea abies) lamella. The experimental tests were carried out for three beam heights: 315,560 , and $810 \mathrm{~mm}$. The beam length is defined according to beam height, which equals $10 \mathrm{~h}$, leading to a span of $8 \mathrm{~h}$ (Fig. 3). All characteristic beam dimensions are listed in Table 2. The support conditions are rotated to ensure uniform compression over the entire surface.

To concentrate the compressive stress perpendicular to the grain and shear stress onto the left support, the loading point is positioned to the left by a distance of $2 \mathrm{~h}$ between the left support and the loading point. Furthermore, to focus on the spreading phenomena occurring near the support, two configurations were selected, both with and without an overhang $(1.5 \mathrm{~h})$, labeled respectively configurations 1 and 2 . Note that the shaded areas are used by the DIC method to obtain full-field displacements during 
the test. The vertical strain can then be calculated with a finite element treatment. The range of contact lengths extends from 50 to $240 \mathrm{~mm}$ (Table 2).

\subsubsection{Methods and experimental protocol}

Three-point bending tests are conducted using a hydraulic press adapted for large spans (over $8 \mathrm{~m}$ ) and heights of over $1 \mathrm{~m}$. The loading system is composed of a hydraulic jack with a 500-kN maximum capacity, an LVDT transducer to track the loading point displacement, plus two additional 500-kN load cells for acquisition of support force. In order to measure the evolution in the mechanical full field by means of the DIC method (Sutton et al. 1983, 1986) in the support areas, the experimental device is supplemented by two CCD cameras and two LED light sources. According to the DIC operating principle, these areas are covered with a black and white speckled pattern. The principle behind this full-field method stems from a comparison between two images acquired during the test, one before deformation and the other one after. The displacement field can then be obtained by comparing the reference image with the deformed image. The experimental procedure is defined according to NF EN 26891 standard.

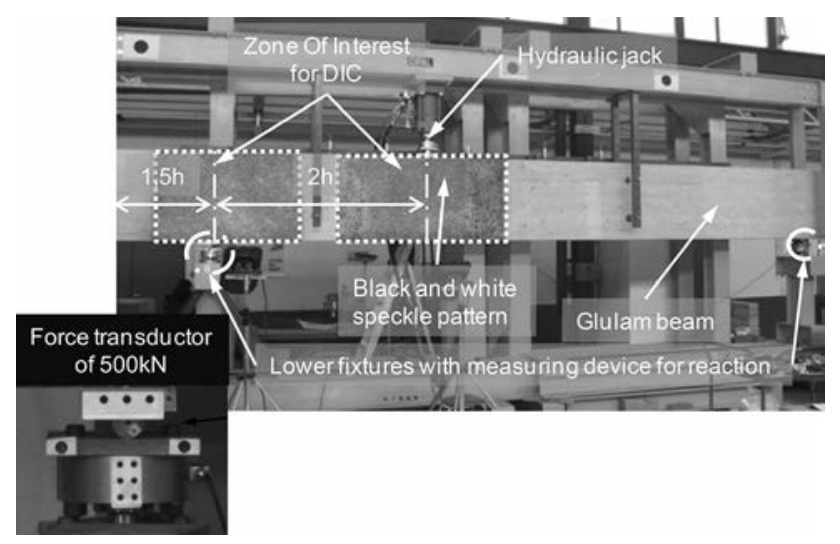

Fig. 3 Experimental bending test under a three-point bending set-up

Table 2 Bending test geometries and results

\begin{tabular}{|c|c|c|c|c|c|}
\hline \multirow[t]{2}{*}{ Configuration } & \multirow[t]{2}{*}{$\mathrm{h}(\mathrm{mm})$} & \multirow[t]{2}{*}{$\mathrm{b}(\mathrm{mm})$} & \multicolumn{2}{|l|}{$l_{s}(\mathrm{~mm})$} & \multirow{2}{*}{$\begin{array}{l}\text { Number of } \\
\text { samples }\end{array}$} \\
\hline & & & Middle & Edge & \\
\hline \multirow[t]{2}{*}{$\mathrm{H}$} & \multirow[t]{2}{*}{810} & \multirow[t]{2}{*}{160} & 240 & 119 & 3 \\
\hline & & & 173 & 119 & 3 \\
\hline $\mathrm{G}$ & \multirow[t]{2}{*}{560} & \multirow[t]{2}{*}{120} & 173 & 119 & 3 \\
\hline $\mathrm{H}$ & & & 240 & 119 & 3 \\
\hline G & \multirow[t]{2}{*}{315} & \multirow[t]{2}{*}{90} & 56 & 50 & 3 \\
\hline $\mathrm{H}$ & & & 56 & 50 & 3 \\
\hline
\end{tabular}

\subsection{Additional tests}

\subsubsection{Uniform compression tests}

In order to understand the stress distribution process in the vicinity of support areas, the knowledge of the local compressive behavior perpendicular to the grain is necessary for both bending and compression configurations. The compression test perpendicular to the grain is carried out according the EN 408 standard and comprises two LVDT transducers placed on each side. Vertical strain is measured from the average displacement using half the specimen height as the reference height $\left(h_{r e f}\right)$. According to EN 408, the uniform compressive strength perpendicular to the grain is estimated from the stress/strain curve (see Fig. 4). The apparent stiffness can also be measured from this setup. The mean of compressive strength perpendicular to the grain $\left(f_{c, 90, \text { mean }}\right)$ is equal to $3.39 \mathrm{MPa}$ in Table 3 , while the mean elastic modulus $\left(E_{c, 90, \text { mean }}\right)$ is $430 \mathrm{MPa}$.

\subsubsection{Compression testing}

To complete the set of tests, a series of compression tests were conducted with the same wood as that of the beams. The compression tests were carried out along the overhang in accordance with EN 408. The load point displacement was controlled at a constant speed of $0.1 \mathrm{~mm} / \mathrm{s}$, as was the case in the uniform compression tests. All specimens were conditioned at $12 \%$ humidity. The digital camera device was used for these tests, like for those discussed above, in order to obtain the deformation field. The recording frame rate per camera equals $0.5 \mathrm{~Hz}$. These series of tests were conducted for configurations B and D (Fig. 2). Configuration $\mathrm{D}$ was tested with the same dimensions, except for width; this test allows visualizing the width effect. Table 3 summarizes the geometries of samples tested and the test results. The compressive stress perpendicular to the grain

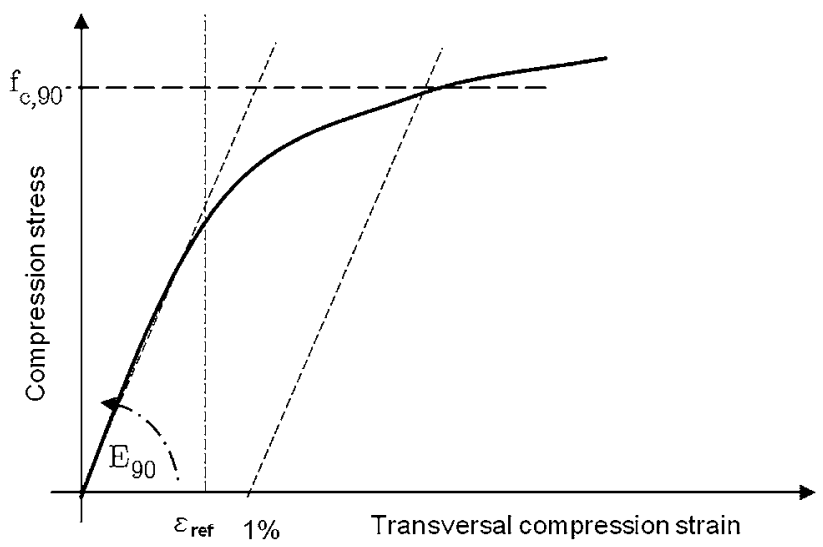

Fig. 4 Vertical strain evolution versus stress, definition of $f_{c, 90}$ 
Table 3 Compression test geometries and results

\begin{tabular}{|c|c|c|c|c|c|c|c|c|}
\hline Configuration & $\mathrm{h}(\mathrm{mm})$ & $\mathrm{b}(\mathrm{mm})$ & $l_{s}(\mathrm{~mm})$ & Number of samples & $\sigma_{c, 1 \%}(\mathrm{MPa})$ & $\mathrm{SD}(\%)$ & $k_{d i f, \exp }$ & $k_{d i f, E C 5}$ \\
\hline A & 200 & 160 & 160 & 35 & 3.39 & 15 & - & - \\
\hline B & 100 & 160 & 50 & 8 & 6.22 & 4 & 1.95 & 3.3 \\
\hline D & 200 & 160 & 50 & 6 & 6.67 & 3 & 1.97 & 3.85 \\
\hline D & 200 & 90 & 50 & 4 & 7.49 & 10 & 2.21 & 3.85 \\
\hline
\end{tabular}

$\left(\sigma_{c}^{1 \%}\right)$ is deducted from the experimental curve deformation/stress, determined at a $1 \%$ plastic strain, as with the uniform compression test. Moreover, the experimental and normative spreading effect is calculated with Eqs. (1) and (3), respectively. Based on the results obtained, a width effect must be taken into account to determine the stress distribution.

\section{Digital image correlation analysis}

\subsection{Distribution of compressive strains perpendicular to the grain}

To highlight the distribution of the mechanical state in the vicinity of support area, the DIC method has been introduced to define the kinematic state around the left support area and application loading area. Figure 5 details the zone of interest (ZOI), composed of optimized correlation windows $16 \times 16$ pixels in size with an amplification factor of 1.5, 1.7 and $0.70 \mathrm{pixel} / \mathrm{mm}$ for 810,560 and 315 beam heights, respectively. As displayed in Fig. 5, the DIC method requires restricting the study height and is unable to approximate the geometric boundaries.

The image capture is performed at a rate of 0.5 frame/s and synchronized with the press data (i.e. force and displacement). The DIC uses integrated processing algorithms in the software correlation developed by the team at the Prime Photomechanical Institute affiliated with the University of Poitiers (France). The software operating principle calls for the integration of a discrete gray level function distributed by pixels forming a regular grid of the digital image. The displacement of various points on the original image can be estimated by correlating information from two successive images. To acquire precise sub-pixels, the gray levels are interpolated by a bilinear function or cubic spline, which allows obtaining a continuous gray level function over the entire image. The ZOI and its displacements are then exported into the Finite Element Software "Castem". The selected displacements are those corresponding to the stress determined at a $1 \%$ plastic deformation calculated with the total height. The mesh rebuilding step using four-node quadratic elements allows calculating the strain tensor distribution. Figure 6 a shows the radial strain component map $\left(\varepsilon_{r r}\right)$ above the left support area, which serves to highlight the spreading effect. The strain fields are then limited by a boundary deformation $\left(\varepsilon_{r e f}\right)$; this limit is determined from the experimental curves between the elastic domain and the plastic domain (Fig. 4).

\subsection{Characterization of height effect}

Figure $6 \mathrm{a}$ is definitely the image that best depicts the main difference between a homogeneous compressive state and a compressive state resulting from a bending configuration with a zone limiting compressive strains perpendicular to the grain. As a matter of fact, the spreading effect is the sign of a height effect, in which vertical strains lie in the elastic domain (clear part). As part of the DIC analysis, now the vertical displacement above the support area is considered. These distributions highlight two specific compressive areas. The first, localized on the lowest onethird height, is characterized by a displacement gradient that proves the existence of a plastic strain; on the other hand, the second zone, localized on the upper two-thirds height, is characterized by a homogeneous vertical displacement that proves the existence of an elastic strain. The analysis is identical for the three heights. It is at variance with the Leijten's analysis.

Figure 6 shows the strain derived from compression tests perpendicular to the grain on both a continuous support (Fig. 6b) and a discrete support (Fig. 6c). For the continuous supports, the plastic height represents halfheight of the sample. For the discrete supports, the plastic total height is symbolized by the sum of two plastic heights of discrete supports. This sum is equal half-height of the sample as can be seen in Fig. 6c.

These remarks regarding the plastic domain allow incorporating the height effect.

\section{Analysis and discussion}

\subsection{Local behavior}

From DIC measurements, the horizontal and vertical displacements can be obtained. From the results of the bending configuration (case $\mathrm{G}$ and $\mathrm{H}$ in Fig. 2), the average 
Fig. 5 Zone of interest and correlation windows in the vicinity of support area
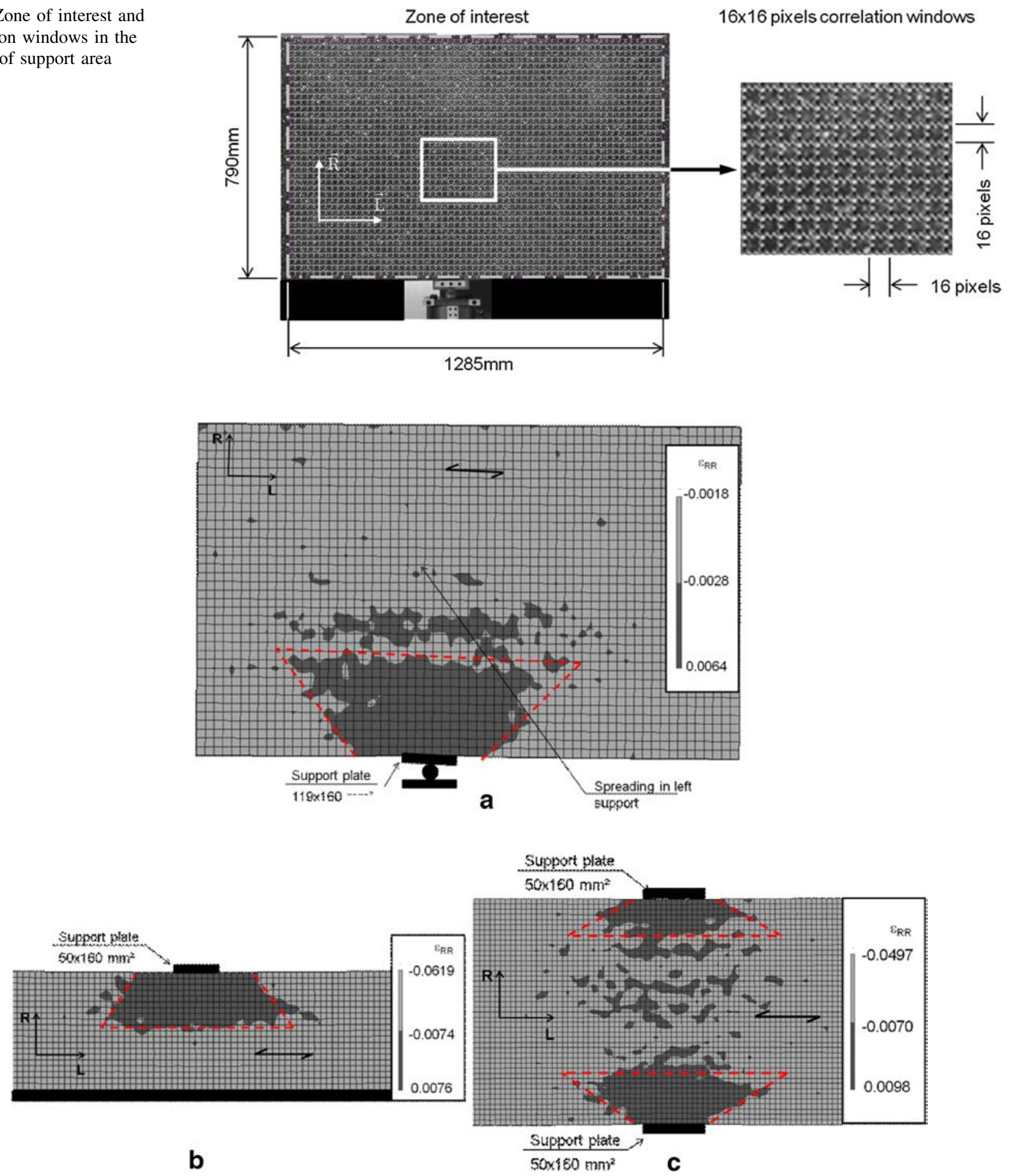

Fig. 6 Radial strain component in the vicinity of support area. a "H" configuration, b "B" configuration, and c "D" configuration

compressive strain perpendicular to the grain $\left(\varepsilon_{c}\right)$ is then calculated by taking into account the displacement of a point localized $\left(u_{r}\right)$ at a reference height equal to $h / 2$, such that:

$\varepsilon_{c}=\frac{u_{r}\left(h_{r e f}\right)}{h}$
That of the compression configuration is calculated as the ratio between the displacement of a load point and the sample's height $(h)$, such that:

$\varepsilon_{c}=\frac{u_{r}}{h}$ 
The compressive stress perpendicular to the grain $\left(\sigma_{c, 90}\right)$ is calculated as the ratio between the support reaction $\left(R_{c, 90}\right)$ and the support surface $\left(A_{c}\right)$, hence:

$\sigma_{c, 90}=\frac{R_{c, 90}}{A_{c}} \quad$ with $\quad A_{c}=l_{s} \cdot b$

These results underscore the difference in stress spreading effect as a function of support length. The standard compression strength, determined at $1 \%$ plastic compressive strain, has been referenced in Tables 3 and 4 according to EN 408. Compared to the mean compressive strength perpendicular to the grain $\left(f_{c, 90, \text { mean }}\right)$ obtained according to EN 408 standard, this result reveals the stress distribution effect.

This factor is calculated for each tested configuration and from the European timber design code. A difference between the two approaches exists. Moreover, for the same support length, the experimental factor is different, yet the factor according to the standard is identical. Consequently, the scale effect has to be considered for the design of spreading effect (Table 4).

\subsection{Spreading phenomenon}

To take into account the spreading effect, Fig. 7 shows the experimental results in terms of support reaction at $1 \%$ plastic strain $\left(R_{c}^{1 \%}\right)$ depending on support length, completed by numerical simulations proposed by Bléron et al. (2009). In considering a given beam geometry, these results indicate a linear relationship between the support reaction at $1 \%$ plastic strain and the support length for a beam of the same width and height. As already shown by Madsen (2000), the following relation is proposed:
Table 4 Limits of compression and $\mathrm{k}_{\mathrm{dif}}$

\begin{tabular}{llllll}
\hline $\mathrm{h}(\mathrm{mm})$ & $l_{s}(\mathrm{~mm})$ & $\sigma_{c, 1 \%}(\mathrm{MPa})$ & $\mathrm{SD}(\%)$ & $k_{\text {dif,exp }}$ & $k_{\text {dif,EC5 }}$ \\
\hline 810 & 240 & 6.05 & 3 & 1.78 & 2.19 \\
& 173 & 6.64 & 2 & 1.96 & 2.36 \\
& 119 & 8.12 & 9 & 2.39 & 2.63 \\
560 & 240 & 5.03 & 4 & 1.48 & 2.19 \\
& 173 & 5.64 & 3 & 1.66 & 2.36 \\
& 119 & 6 & 4 & 1.77 & 2.63 \\
315 & 56 & 7.26 & 4 & 2.14 & 3.63 \\
& 50 & 8.64 & 4 & 2.55 & 3.85 \\
\hline
\end{tabular}

$R_{c}^{1 \%}=a_{1} \cdot l_{s}+b_{1}$

Linear coefficients $a_{1}$ and $b_{1}$ are given in Table 5 . When considering Eq. (6), the expression in (7) can be rewritten in terms of stress as follows:

$\sigma_{c}^{1 \%}=\frac{a_{1}}{b}+\frac{b_{1}}{b \cdot l_{s}}$

Equation (8) is composed of two terms. The first one is predominant for a large support length. In this case, the compression state becomes homogeneous without any distribution process and corresponds to the mean compressive strength perpendicular to the grain, such that:

$f_{c, 90, \text { mean }}=\lim _{l_{s} \rightarrow \infty} \sigma_{c}^{1 \%}=\frac{a_{1}}{b}$

According to (9), $a_{1}$ admits the following definition:

$a_{1}=f_{c, 90, \text { mean }} \cdot b$

The second term relates to the effect of a small support length; it corresponds to a shear stress induced by the

Fig. $7 \mathrm{R}_{\mathrm{c}}^{1 \%}$ versus $1_{\mathrm{s}}$

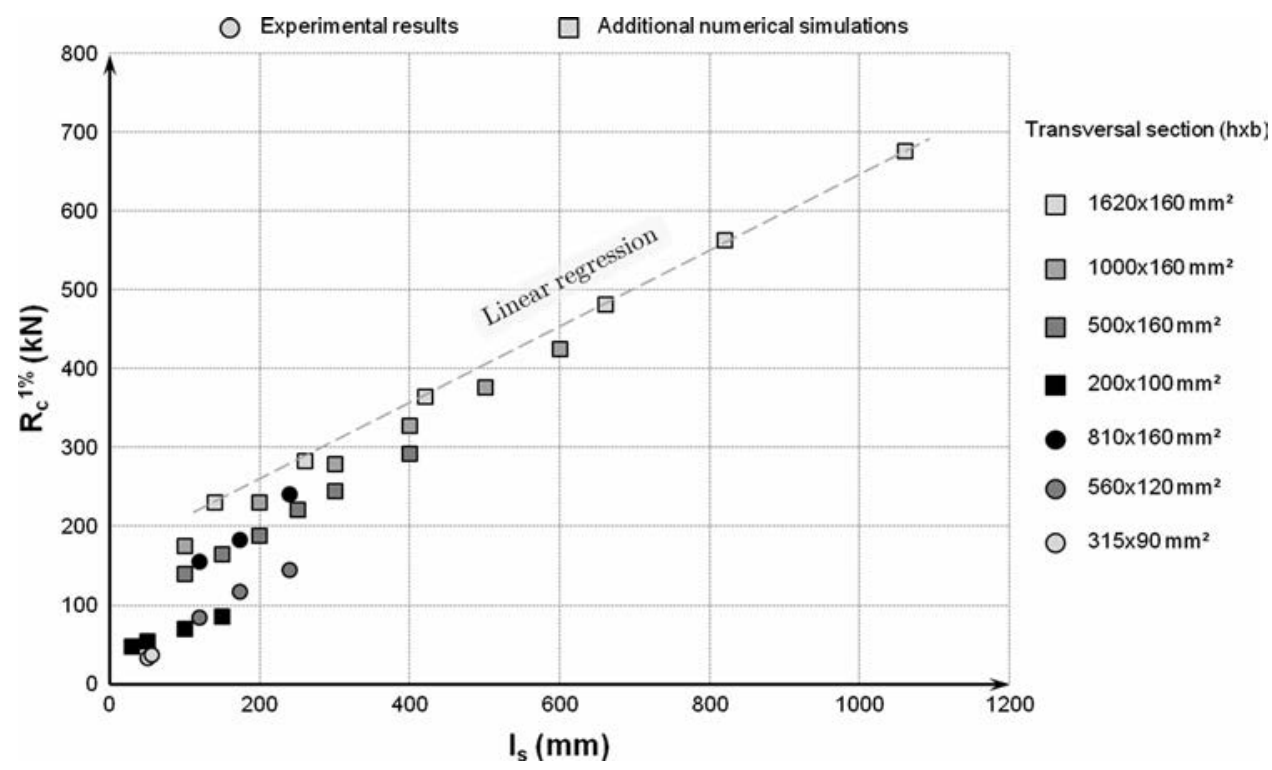


Table 5 Linear regression parameters

\begin{tabular}{lllrl}
\hline $\mathrm{h}(\mathrm{mm})$ & $\mathrm{t}(\mathrm{mm})$ & $\mathrm{a}_{1}(\mathrm{~N} / \mathrm{mm})$ & $\mathrm{b}_{1}(\mathrm{~N})$ & $\mathrm{R}^{2}$ \\
\hline 1620 & 160 & 0.485 & 160.0 & 0.9981 \\
1000 & 160 & 0.494 & 130.0 & 0.9996 \\
810 & 160 & 0.718 & 66.0 & 0.9811 \\
560 & 120 & 0.534 & 18.9 & 0.9786 \\
500 & 160 & 0.518 & 87.7 & 0.9978 \\
315 & 90 & 0.577 & 4.3 & 1 \\
200 & 100 & 0.313 & 38.6 & 1 \\
\hline
\end{tabular}

support edge. Under these conditions, Eq. (7) is simplified as follows:

$\lim _{l_{s} \rightarrow 0} R_{c}^{1 \%}=b_{1}$

For this case, the term $b_{1}$ denotes the shear force for a very small support. Today according to the continuum mechanics, the mean shear strength $\left(f_{v, \text { mean }}\right)$ can be written as follows:

$f_{v, \text { mean }}=\frac{3}{2} \cdot \frac{b_{1}}{b \cdot h} \Leftrightarrow b_{1}=\frac{2}{3} \cdot f_{v, \text { mean }} \cdot b \cdot h$

Moreover, combining Eqs. (8), (10) and (12) the compressive stress perpendicular to the grain takes the following global form:

$\sigma_{c}^{1 \%}=f_{c, 90, \text { mean }}+f_{\mathrm{v}, \text { mean }} \cdot \frac{h}{l_{s}} \cdot \frac{2}{3}$

This formalism has been applied to all experimental bending studies (Fig. 8). Moreover, the Eurocode 5 criterion is integrated in Fig. 8. This integration allows seeing the difference between the experimental results at the $1 \%$ plastic strain and the Eurocode 5 criterion. Consequently, the Eurocode 5 criterion is not safe for small heights. Another difference remains between the application of Eq. (13) and the experimental results prompting to anticipate a scale effect relative to shear and compression coupling. With these considerations, now a scale effect is introduced, through a scale factor $\left(\mathrm{k}_{\text {scale }}\right)$, such that:

$\sigma_{\mathrm{c}}^{1 \%}=\mathrm{f}_{\mathrm{c}, 90, \text { mean }}+\mathrm{f}_{\mathrm{v}, \text { mean }} \cdot \frac{\mathrm{h}}{\mathrm{l}_{\mathrm{s}}} \cdot \frac{2}{3} \cdot \mathrm{k}_{\text {scale }}$

The scale effect must integrate corrections specific to local beam geometry in the vicinity of the support area, including height, width, distribution conditions and support conditions. Based on the various tests, the height effect $\left(\mathrm{k}_{\mathrm{h}}\right)$ can be discussed. This effect is introduced through previsualizations of different strain fields. Shear had previously been introduced by taking into account total sample height. With the deformation fields, it is only possible to visualize a third of the height for bending tests

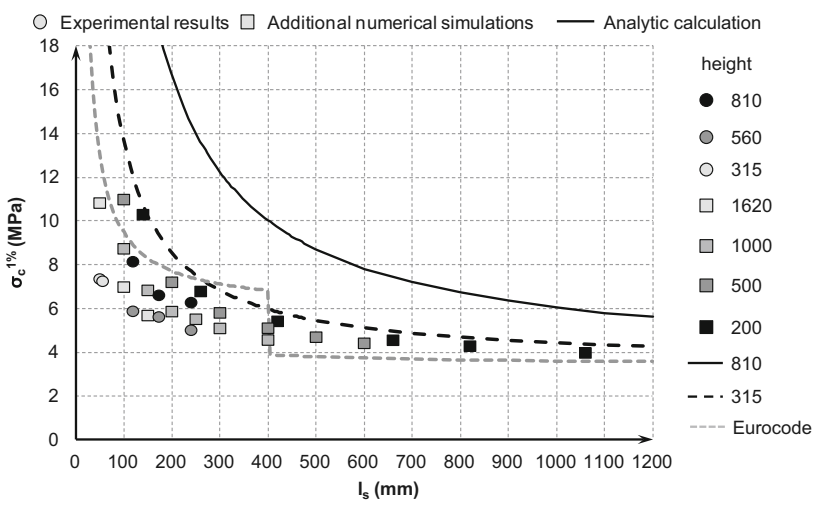

Fig. $8 \sigma_{c}^{1 \%}$ prediction versus $1_{\mathrm{s}}$, analytical and experimental results

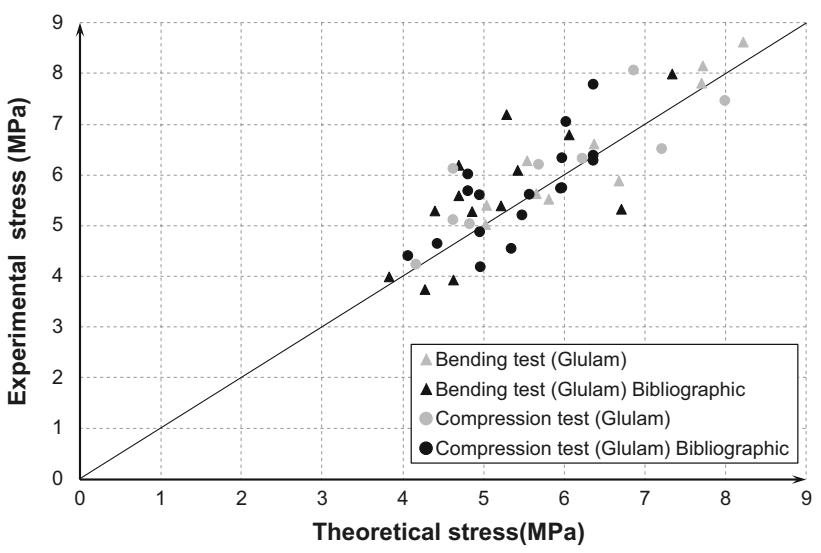

Fig. 9 Review of all mean model predictions versus mean test results

and a half-height compression test involved in the force spreading through the material. This factor acknowledges the percentage of the height involved in the force spreading and can be expressed as follows:

$\mathrm{k}_{\mathrm{h}}= \begin{cases}\frac{1}{3} & \text { cases in bending } \\ \frac{1}{2} & \text { the other cases }\end{cases}$

In contrast, the model must take into account the number of distribution sides. Two tests were performed using the same dimensions and only changing the configuration. The first one considers that the support is an intermediate support, with force spreading possible on either side of the support. The second configuration considers the support as an end support, restricting distribution to just one side. The factor taking into account the number of distribution sides has thus been integrated; the factor $\left(\mathrm{n}_{\mathrm{d}}\right)$ can now be written as follows:

$\mathrm{n}_{\mathrm{d}}= \begin{cases}1 & \text { end supports } \\ 2 & \text { intermediate supports }\end{cases}$ 
The analytical model should exhibit the sample width effect $\left(\mathrm{k}_{\mathrm{t}}\right)$ noticed above; it is expressed by a test width set to a power. This factor assumes the following form regardless of the loading configuration:

$\mathrm{k}_{\mathrm{b}}=\mathrm{b}^{-0.325}$

This latter factor $\left(\mathrm{k}_{\mathrm{sc}}\right)$ is introduced in addition to the two other distinct values. Support conditions can now be ascribed a value, one for discrete supports and one for continuous supports. This factor assumes the value:

$\mathrm{k}_{\mathrm{sc}}= \begin{cases}1.51 & \text { configuration }(\mathrm{C}, \mathrm{D}, \mathrm{E}, \mathrm{G}, \mathrm{H}) \\ 1.85 & \text { configuration }(\mathrm{B}, \mathrm{F})\end{cases}$

These last two factors are found using linear regression analysis. In order to determine the optimum value, the data used are the current test results of bending and compression configurations. According to an optimization algorithm between Eq. (14), experimental results and complementary simulations, it was opted for the following scale factor form:

$\mathrm{k}_{\mathrm{scale}}=\mathrm{k}_{\mathrm{h}} \cdot \mathrm{k}_{\mathrm{b}} \cdot \mathrm{k}_{\mathrm{sc}} \cdot \mathrm{n}_{\mathrm{d}}$

The design approach can be homogenized in terms of compression criterion perpendicular to the grain in accordance with Eq. (6). From the compressive stress, Eq. (14), the spreading factor can also be defined as follows:

$\mathrm{k}_{\text {dif }}=1+\frac{\mathrm{f}_{\mathrm{v}, \text { mean }}}{\mathrm{f}_{\mathrm{c}, 90, \text { mean }}} \cdot \frac{\mathrm{h}}{\mathrm{l}_{\mathrm{s}}} \cdot \frac{2}{3} \cdot \mathrm{k}_{\text {scale }}$

A comparison of the compressive stress at $1 \%$ plastic strain from experimental results and analytical solutions, i.e. Eq. (14), is presented in Fig. 9. Based on the uniform test according to EN 408 standard, the mean compressive strength perpendicular to the grain takes the values of 3.39 $\mathrm{MPa}$. Concerning the shear strength, it is calculated from EN 1990 standard and EN 14080 standard. The EN 1990 standard allows calculating the mean value of mechanical properties from the characteristics value and

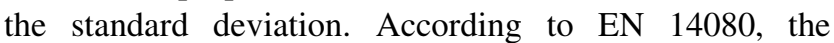
characteristic value of shear strength is equal to $3.5 \mathrm{MPa}$ for the standard deviation from 20 to $25 \%$ according to estimates. Consequently, the mean value of the shear strength can be taken equal to $4.92 \mathrm{MPa}$. In applying the model, a $9 \%$ difference remains with respect to the experimental values.

\section{Conclusion}

This work has proposed a new approach based on introducing the spreading effect. This study has demonstrated the need to take into account coupling of the effects of compressive stress perpendicular to the grain with the shear state and scale effect to understand the spreading effect for the structural glued laminated timber. The limit compressive stress perpendicular to the grain is reflected in a constraining criterion applied to the design of support area, as for the European timber design code, thereby resolving the problem of using glued laminated timber elements for large spans. However, the actual code integrates the spreading effect by the fixed values without taking any scale effect into account. Because of this, the support lengths of large-spanned structures are penalized. Moreover, diffusion effects tend to predominate as the supports become wide. To reduce the support surface area for large spans, it would appear necessary to explore constructive solutions in order to increase local compressive strength perpendicular to the grain coupled with a shear state. These solutions may involve reinforcement in the vicinity of the support area through use of specific panels or reinforcement screws.

Acknowledgments Our gratitude is extended to the staff and technicians of the Civil Engineering Department at the University of Limoges (France) for their collaboration in conducting the campaign of bending tests. Special appreciation goes to Jérôme Dopeux, Hamidou Sebbah and Jany Cacault for their close involvement in this work program. We would also like to thank the Professional Development Committee of the French Furniture and Wood Industries Association for funding these tests. Moreover, this project has benefited from encouragements received from the "ARBRE" Laboratory of Excellence.

\section{References}

Augustin M, Ruli A, Brandner R, Schickhofer G (2006) Behavior of glulam in compression perpendicular to grain in different strength grades and load configurations. In: CIB-W18, paper 39-12-6, Florence, Italy

Blass H-J, Bejtka I (2004) Reinforcements perpendicular to the grain using self-tapping screws. In: WCTE, vol 1, Helsinki, Finland. http://www.rz.uni-karlsruhe.de/ gc20/IHB/PUBLIC/37.pdf

Blass H-J, Görlacher R (2004) Compression perpendicular to the grain. In: WCTE, pp 14-17, Helsinki, Finland. http://www.rz. uni-karlsruhe.de/ gc20/IHB/PUBLIC/35.pdf

Bléron L, Cabaton L, Sauvignet E (2009) Compression perpendicular at the grain, mechanical tests-modelling. In: CFM, Bordeaux, France

Ed D, Hasselqvist F (2011) Timber compression strength perpendicular to the grain. Lund Institute of Technology, Lund

Kollmann F (1955) Technology of wood and wood based materials. Springer, Berlin (in German)

Leijten AJM, Jorissen AJM, de Leijer BJC (2012) The Local bearing capacity perpendicular to grain of structural timber elements. Constr Build Mater 27(1):54-59

Madsen B (1992) Structural behavior of timber. Timber Engineering, North Vancouver

Madsen B (2000) Behavior of timber connections. Timber Engineering, Vancouver

Mähr M (2002) Reinforcement of compression perpendicular to the grain with self-tapping screws. Fachhochschule Liechtenstein, Vaduz (in German) 
Nilsson K (2002) Reinforcement of wood by screws loaded perpendicular to the grain. In: Fiberriktningen. Rapport TVBK-5112. Lunds Tekniska Högskola, Lund (in Swedish)

Reichegger M (2004) Compression perpendicular to the grain in structural elements according to the new standard proposal. Universitá degli Studi di Trento, Trento (in Italian)

Riberholt H (2000) Compression perpendicular to the grain of wood. COWI-report 42239-1

Sutton MA, Wolters W, Peters WH, Ranson WF, McNeil SR (1983) Determination of displacements using an improved digital correlation method. Image Vis Comput 1(3):133-139
Sutton MA, Cheng MQ, Peters WH, Chao YJ, McNeil SR (1986) Application of an optimized digital correlation method to planar deformation analysis. Image Vis Comput 4(3):143-151

Van der Put TACM (2008) Derivation of the bearing strength perpendicular to the grain of locally loaded timber blocks. Delft Wood Sci Found 66(6):409-417 